\title{
A crítica dialética de Theodor Adorno ao fascismo: implicações no campo formativo
}

\author{
The dialectical critique of Theodor Adorno about fascism: implications in formation
}

La dialéctica crítica de Theodor Adorno al fascismo: implicaciones en la formación

SINÉSIO FERRAZ BUENO*

$\longrightarrow$

\begin{abstract}
RESUMO
A análise de Theodor W. Adorno ao fascismo aparece como um dos temas mais importantes da Teoria Crítica, pois esse filósofo dedicou ao assunto uma parte expressiva de sua obra intelectual. Nessa reflexão, o conceito freudiano de unheimlich teve um papel fundamental, pois permitiu a compreensão da relação ambivalente no que diz respeito a estranhos e estrangeiros, na consideração de que o diferente repele e ao mesmo tempo é internamente familiar. $\mathrm{Na}$ análise crítica de Adorno sobre o fascismo, a estigmatização da diferença, impulsionada pela incapacidade de compreensão e aceitação dos próprios conteúdos pulsionais do sujeito, acarreta o desenvolvimento de fortes tendências de segregação, que adquirem coloração fascista sempre que se manifestam como oposições in-group e out-group. Este artigo pretende repercutir a importância dessa análise no campo educativo, em especial no que se refere a possibilidades autorreflexivas no campo formativo.
\end{abstract}

Palavras-chave: Theodor Adorno. Fascismo. Teoria Crítica. Unheimlich. Psicanálise.

\begin{abstract}
The analysis of Theodor W. Adorno on fascism appears as one of the most important themes of Critical Theory, as this philosopher devoted to the subject a significant part of their intellectual work. In this reflection, the freudian concept of unheimlich played a key role because it allowed the understanding of ambivalent forward toward strangers and foreigners, on the consideration that the different repels while internally is familiar. In Adorno's critical analysis of fascism stigma of difference, driven by the understanding of disability and acceptance of own instinctual contents of the subject, entails the development of strong segregation trends, acquiring fascist coloration whenever manifest as in-group opposition and out-group. This article aims to reflect the importance of this analysis in the educational field, particularly as regards the autoreflexivas possibilities in formation.
\end{abstract}

Keywords: Theodor Adorno. Fascism. Critical Theory. Unheimlich. Psychoanalysis.

\section{RESUMEN}

El análisis de Theodor W. Adorno al fascismo aparece como uno de los temas más importantes de la Teoría Crítica, ya que este filósofo dedicado al tema una parte importante de su trabajo intelectual. En esta reflexión, el concepto freudiano de unheimlich jugó un papel clave, ya que permite la comprensión de la ambivalencia hacia delante, hacia los extraños y extranjeros, en la consideración de que los diferentes repele mientras que internamente está familiarizado. En el análisis crítico de Adorno del estigma fascismo de la diferencia, impulsado por la comprensión de la discapacidad y la aceptación de los propios contenidos pulsionales del sujeto, implica el desarrollo de fuertes tendencias de segregación, adquiriendo una coloración fascista cada vez que se manifiestan como en grupo de la oposición y fuera del grupo. En este artículo se pretende reflejar la importancia de este análisis en el campo de la educación, especialmente en lo que se refiere a las posibilidades autoreflexivas en formación.

Palabras clave: Theodor Adorno. El fascismo. Teoría Crítica. Unheimlich. Psicoanálisis.

\footnotetext{
* Doutor em História e Filosofia da Educação pela Universidade de São Paulo, Brasil. Professor Assistente Doutor da Universidade Estadual Paulista Júlio de Mesquita Filho, Brasil.E-mail: <sinesioferraz@yahoo.com.br>.
} 


\section{INTRODUÇÃO}

No prefácio da Dialética do esclarecimento, os pensadores alemães Adorno e Horkheimer explicitam, juntamente com o significado central de sua obra mais consagrada e filosoficamente consistente, igualmente, a ruptura com o otimismo iluminista perante os potenciais emancipadores da razão. Ao afirmarem o propósito de "descobrir por que a humanidade, em vez de entrar em um estado verdadeiramente humano, está se afundando numa espécie de barbárie" (1985, p. 11), os filósofos apontam para o caráter dialético do esclarecimento. Dessa forma, anunciam também uma ruptura em relação à concepção hegeliana da história como progresso infalível do espírito.

Como se sabe, o pano de fundo histórico que justificou a constatação sombria de ambos os pensadores foi suficientemente eloquente para que sua reflexão filosófica apresentasse a tese que explica a barbárie não como desvio em relação a um caminhar evolutivo da humanidade, mas como resultado necessário do próprio progresso técnico e científico. Quando se consideram os aspectos decisivos representados pelos acontecimentos históricos que animaram sua reflexão filosófica, a proposição acerca do caráter irredutivelmente dialético do esclarecimento é inseparável dos processos de aniquilação da vida contemporâneos à escrita da obra citada, os quais podem ser resumidamente sintetizados pela ascensão progressiva da barbárie do fascismo.

Sob tal perspectiva, o fascismo e sua crítica teórica e prática emergiram como o mais urgente dos temas para os dois pensadores, que a ele dedicaram parte expressiva de sua obra intelectual. Não é por caso que, na parte final da Dialética do esclarecimento, os filósofos refletem sobre a conexão entre a epistemologia positivista e a paranoia, propondo o comprometimento do sujeito cognoscente pela patologia de natureza emocional. Sob essa chave de leitura, o conhecimento científico seria uma atividade estruturalmente corrompida por impulsos paranoicos e totalitários de domínio do objeto, inteiramente alheios a processos de autorreflexão. A restituição do compromisso ético do conhecimento dependeria, segundo os filósofos, de processos reflexivos capazes de "elaborar intelectualmente o fracasso da pretensão absoluta", pois somente assim seria possível a superação da "pretensão que levou seu juízo ao fracasso" (1985, p. 181).

O vínculo entre conhecimento e delírio paranoico, acompanhado pela alergia intelectual a pensamentos capazes de autorreflexão explicaria as tendências regressivas intrínsecas à razão esclarecida, oferecendo uma compreensão da dialética do esclarecimento que não se restringe ao repertório conceitual da filosofia, uma vez que a ideia fixa peculiar à atividade paranoica, sendo animada por delírios de grandeza e sentimentos persecutórios, é explicada mediante a mobilização de conceitos da psicanálise, em especial o de pulsão de morte. Sob essa perspectiva, o pensamento de Freud aparece como subsídio fundamental na Dialética do esclarecimento, notadamente pela repercussão do conceito de projeção para a análise dos fundamentos pulsionais inerentes ao fascismo.

Nesse sentido, um conceito específico apresentado por Freud para refletir sobre a relação ambivalente no que diz respeito a estranhos ou estrangeiros adquire grande relevância na análise de Adorno e Horkheimer, notadamente pela importância que teria nas reflexões posteriores sobre o fascismo. Trata-se do conceito de unheimlich, cuja natureza projetiva é explicitada pelos pensadores em suas reflexões sobre o antissemitismo: "O que repele por sua estranheza é, na verdade, demasiado familiar" (1985, p. 170).

\section{UNHEIMLICH, FASCISMO E ESTIGMATIZAÇÃO DA DIFERENÇA}

Em suas reflexões sobre o conceito de unheimlich, Freud enfatizou a ambiguidade semântica do termo, que em língua portuguesa equivale a "estranho" ou "estrangeiro", pois remete simultaneamente a uma estranheza que, ao mesmo tempo em que assusta e horroriza, expressa sentimentos e desejos familiares ao sujeito, embora inconscientes. A ambivalência desse conceito é essencial para se compreender a análise do fascismo na dialética do esclarecimento, pois esclarece a mobilização de conteúdos internos reprimidos, inconscientes, e, portanto, desconhecidos pelo sujeito, na relação com a diferença, sob diversos registros, notadamente sob aspectos étnicos, raciais e sexuais. Essa dimensão ameaçadora dos próprios desejos reprimidos do sujeito leva a uma relação tortuosa, que, por meio do mecanismo de defesa da projeção, conduz a uma representação perversa do outro, que então é visto como sujo, promíscuo ou inferior. A estigmatização da diferença, impulsionada pela incapacidade de compreensão e aceitação dos próprios conteúdos pulsionais do sujeito, acarreta o desenvolvimento de fortes tendências de segregação, que adquirem coloração fascista sempre que se manifestam como oposições in-group e out-group, as quais, conforme será abordado, foram fundamentais na crítica de Adorno ao fascismo.

$\mathrm{Na}$ Dialética do esclarecimento, a rejeição da diferença, impulsionada por essa ambivalência peculiar à relação com estranhos e estrangeiros, configurou a hostilidade assassina típica do antissemitismo nazifascista, servindo como pano de fundo explicativo para a configuração da "paranoia como sombra do conhecimento" (1985, p. 182). Esse tipo de hostilidade preconceituosa e segregadora, 
que se abateu sobre a população judaica, no contexto histórico específico do nazifascismo, pode igualmente se manifestar sobre outras populações em outros contextos históricos ou geopolíticos, delimitando o fascismo como conceito de natureza psicossocial, que não se restringiu ao delírio antissemita. Adorno e Horkheimer são claros em apontar a plasticidade peculiar à estranheza inaceitável em sua propriedade de se abater sobre os mais diversos tipos de categoria social. As vítimas são "intercambiáveis segundo a conjuntura: vagabundos, judeus, protestantes, católicos, cada uma delas (está assim no original?) pode ocupar o lugar do assassino, na mesma volúpia cega do homicídio, tão logo se converta na norma, e se sinta poderosa enquanto tal" (1985, p. 160).

As dificuldades humanas na relação com a diferença sob os mais diversos tipos de recorte podem ser sucintamente compreendidas à luz da dualidade freudiana entre pulsões de vida e pulsões de morte e suas implicações para o contato entre grupos culturais. Segundo a abordagem de Freud, populações vizinhas apresentam fortes inclinações no sentido de hostilizarem estrangeiros e ao mesmo tempo identificarem-se mutuamente no interior da comunidade. Trata-se do conceito de "narcisismo das pequenas diferenças", proposto por Freud para explicar as fortes tendências de supervalorização de pequenas diferenças em relação a comunidades habitantes de territórios adjacentes, produzindo uma estrangeiridade negativa, de maneira a permitir o escoamento das pulsões agressivas para fora, o que permite que no interior da comunidade prevaleçam laços de fraternidade, mútua identificação e solidariedade.

Para Freud, é graças à existência do estrangeiro, a personificar a estranheza e a diferença, que uma comunidade pode manter-se unida e mutuamente identificada: "É sempre possível unir um considerável número de pessoas no amor, enquanto sobrarem outras pessoas para receberem as manifestações de agressividade" (1974, p. 136). As oposições in-group/ out-group assim formadas foram consideradas por Adorno o veículo emocional que conduz à canalização de pulsões agressivas e de maciça hostilização contra minorias étnicas, raciais ou sexuais cuja manifestação caracteriza a barbárie fascista. Sob esse aspecto, em uma leitura fortemente inspirada em Freud, Adorno analisa o fascismo como formação grupal potencialmente produtora de delírios coletivos de estigmatização da diferença baseados em oposições grupais construídas mediante a depreciação sistemática do unheimlich. Dessa maneira, o combate ao fascismo requer a conscientização racional pelo sujeito acerca do caráter patologicamente projetivo que o impede de reconhecer o familiar no estranho. Sob esse ponto de vista, transparece com clareza a completa insuficiência de se combater o fascismo mediante uma simplória inversão de estereótipos, pois, para Adorno, "liberdade seria não eleger entre preto e branco, mas sair dessa escolha pré-estabelecida" (2008, p. 128). Assim, o antídoto mais eficaz ao fascismo, vale dizer, uma "sociedade emancipada", seria "a realização do universal na reconciliação das diferenças" (2008, p. 99).

\section{TEORIA FREUDIANA E ANÁLISE DO FASCISMO}

Em seus textos datados da década de 1950, especificamente dedicados ao estudo da personalidade autoritária e do fascismo, Adorno empenhou-se em compreender os procedimentos mobilizados por líderes grupais no sentido de reforçar sistematicamente imagens estereotipadas de depreciação de minorias étnicas, raciais e de imigrantes em geral. Partindo do pressuposto segundo o qual as raízes do problema devem ser buscadas nos agentes do preconceito e não nas vítimas, Adorno empregou os conceitos propostos por Freud em sua obra Psicologia de massas e análise do eu para explicar os motivos da eficiência da retórica do líder fascista para convencer e seduzir as multidões.

Um dos fatores centrais envolvidos no fenômeno diz respeito às demandas narcísicas que a idealização do líder por parte de seus seguidores promete realizar. Sobre essa questão, Adorno explicita a questão fundamental proposta por Freud, cuja resposta é de importância crucial para uma compreensão adequadamente crítica do problema: "Por que os seres humanos modernos retornam a padrões de comportamento que contradizem flagrantemente seu próprio nível racional e o presente estágio da civilização tecnológica esclarecida”? (2015, p. 159). Em outras palavras, trata-se de entender como é possível que "indivíduos, filhos de uma sociedade liberal, competitiva e individualista, condicionados a se manterem como unidades independentes e autossustentadas" tenham sua individualidade diluída, aceitando fazer parte de um aglomerado homogêneo de membros de multidões fascistas? $(2015$, p. 158). A elucidação dessa contradição entre o grau de maturidade racional e as tendências à regressão coletiva requer considerar o teor de gratificação emocional proporcionada pela adesão a esse tipo de coletivo.

Para Adorno, a sociedade liberal, ao mesmo tempo em que estimula o senso de independência, de competição e de autopreservação, nega aos mesmos indivíduos as possibilidades materiais de realização efetiva de tais ideais. Os impulsos narcisistas, impossibilitados de realização, encontram uma satisfação substitutiva por meio da idealização da figura do líder, que sob esse aspecto personifica uma espécie onipotente de "pai primitivo da horda". Pela idealização, "o sujeito ama a si mesmo", 
livrando-se "das manchas de frustração e mal-estar que desfiguram a imagem de seu próprio eu empírico" (2015, p. 169).

A gratificação emocional proporcionada pela idealização do líder fascista, em sua qualidade de satisfazer fortes impulsos narcisistas socialmente gerados, porém jamais satisfeitos, é corroborada e intensificada pela possibilidade adicional de satisfação de um prazer de natureza sadomasoquista peculiar que consiste em respeitar as elites poderosas e ao mesmo tempo hostilizar as minorias fracas e desamparadas. Adorno enfatiza a pertinência e a produtividade da abordagem de Freud, que foi capaz de intuir conceitualmente o surgimento do fenômeno do fascismo duas décadas antes de sua nefasta concretização histórica. A dicotomia entre o amado ingroup e o odiado out-group, sugerida nas reflexões sobre a natureza projetiva envolvida na aversão ao unheimlich e nas idiossincrasias próprias ao "narcisismo das pequenas diferenças", foi suficiente para que Freud dedicasse às esperanças emancipadoras depositadas pela cultura burguesa no progresso da razão nada menos do que um amargo ceticismo.

Adorno sintetiza, a esse respeito, certa versão freudiana de uma dialética do esclarecimento: "Já em 1921 ele foi, portanto, capaz de dispensar a ilusão liberal de que o progresso da civilização iria produzir automaticamente um aumento de tolerância e uma diminuição de violência contra os out-groups" (2015, p. 174). A oposição rígida e maniqueísta entre grupos não somente permite ao agente do preconceito e da hostilidade fascista ganhos narcisistas originados da compensação imaginária de suas frustrações reais, que o fazem sentir-se superior, melhor e mais puro do que os excluídos, como também representa um obstáculo dificilmente transponível contra questionamentos de natureza crítica a suas ideias e valores preconcebidos: "Qualquer tipo de crítica ou autoconsciência é ressentida como uma perda narcisista e incita fúria" $(2015$, p. 177). Essa "síndrome fascista", detalhadamente analisada em Personalidade autoritária pelo filósofo, revela assim uma de suas características mais salientes: a hostilidade aberta a reflexões intelectuais e comportamentos introspectivos.

A mobilização dos processos emocionais, inconscientes e regressivos por parte do líder fascista, e sua eficiência no sentido de proporcionar satisfações de natureza narcisista compensadoras das frustrações reais experimentadas por seus seguidores, envolve, segundo Adorno, uma completa inversão dos procedimentos e objetivos propriamente educativos da teoria freudiana. Esta justificou-se nos termos de sua adesão explícita nos moldes do iluminismo filosófico como emancipação do homem do domínio heterônomo do inconsciente, horizonte sintetizado por Freud em sua máxima: "O que é isso deve se tornar eu" (2015, p. 187). O fascismo, por outro lado, persegue objetivos diametralmente opostos, buscando perpetuar um estado de dependência do eu racional em relação a seus processos inconscientes. Sob esse aspecto, é pertinente apontar o caráter radicalmente antieducativo da liderança fascista, em seu empenho sistemático de neutralização dos potenciais emancipadores latentes na sociedade burguesa, uma vez que o conjunto do fenômeno apresenta a tendência de perpetuar o controle social, "em lugar de tornar os sujeitos conscientes de seu inconsciente" (2015, p. 187).

Adorno refere-se ao empobrecimento psicológico do sujeito como característica das mais relevantes e lamentáveis ocasionadas pela disseminação do fascismo na sociedade burguesa, não somente pelo estado geral de heteronomia emocional sistematicamente induzido pela retórica monótona e repetitiva do líder fascista, como também pelas tendências prévias de neutralização da autorreflexão que são intrínsecas ao processo como um todo. Resumindo o clima cultural geral de diluição da própria substância psicológica do indivíduo burguês, o qual um dia justificara o otimismo kantiano nos potenciais de maioridade intelectual próprios a uma era iluminista, Adorno caracteriza os homens-massa como "átomos sociais desindividualizados e pós-psicológicos que formam as coletividades fascistas" (2015, p. 187).

\section{DiALÉTICA DO FASCISMO}

A eficiência da retórica disseminada pelo líder fascista, embora tenha sido sinistramente comprovada por diversos acontecimentos históricos do século XX, dentro e fora do mundo ocidental, está inserida em uma dialética que aponta necessariamente para possibilidades de superação e de negação potencialmente disponíveis aos mesmos átomos desindividualizados citados por Adorno. Essa perspectiva de superação é, na verdade, sua principal contribuição para uma leitura crítica sobre o fascismo. A compreensão dessa dialética intrínseca ao fascismo requer que se atente para o fato de que, ao comentar a reação furiosa do seguidor fascista a conteúdos críticos voltados contra seu comportamento, a reação violenta é explicada em função de seu potencial de desmascaramento de "valores obstinadamente mantidos" (ADORNO, 2015, p. 181).

Atendo-se ao efeito de "impostura" que de acordo com Freud permanece existindo em estado latente, durante fenômenos de hipnose induzidos pelo analista, Adorno ressalta a caracterização freudiana da psicologia de grupo como situação analogamente hipnótica na relação entre o líder e seus seguidores. Dessa forma, considerando que o fenômeno do fascismo envolve uma coletivização do "feitiço hipnótico", a ele igualmente é cabível a existência 
de uma consciência latente acerca do logro implícito nessa apropriação da psicologia de massas pelo líder fascista.

Na observação da consciência latente dos integrantes das massas fascistas sobre a impostura implícita no processo, Adorno consegue compreender o fenômeno do fascismo em sua mais íntima natureza, desvendando, ao mesmo tempo, os potenciais intrínsecos de superação desse tipo de adesão. O comportamento histérico das massas fascistas encobre uma identificação psicológica que não é tão autêntica quanto faz parecer, constituindose, antes, como simulação psicologicamente necessária. Tal simulação visa a atender a necessidades de integração social em um contexto histórico da sociedade liberal que envolve a mobilização de demandas altamente ambíguas e dificilmente conciliável pelas massas, pois "é através dessa encenação que elas atingem um equilíbrio entre seus ímpetos pulsionais continuamente mobilizados e o estágio histórico de esclarecimento que elas alcançaram e que não pode ser revogado arbitrariamente" (ADORNO, 2015, p. 188).

Em sua análise da paranoia antissemita, na obra Dialética do esclarecimento, Adorno, juntamente com Horkheimer, havia igualmente analisado que esta não se explica em função do comportamento emocional projetivo em si mesmo, mas da ausência de reflexão que o acompanha, o que justifica o emprego do termo "falsa projeção" como qualificativo mais adequado para designar a relação do fascista com o unheimlich. Nesse sentido, analisam os filósofos, o comportamento anti-introspectivo, indutor de uma sintomática alergia a apontamentos críticos por dirigidos ao fascista, os quais poderiam fomentar pensamentos autorreflexivos, explica-se como mecanismo de defesa mobilizado contra o pânico que poderia ser suscitado caso a impostura fosse desmascarada: "O olhar não paranoico, confiante, recorda-lhes o espírito que se extinguiu dentro delas, porque, fora delas, só enxergam a frieza dos meios de autoconservação" (1985, p. 178). A recusa prévia de conteúdos críticos em relação a atitudes e comportamentos dos adeptos do fascismo justifica-se igualmente em virtude do caráter ambivalente do unheimlich, composto de estranheza e proximidade. Atitudes autocríticas tornam-se ameaçadoras por um duplo motivo, sugerindo tanto a dissolução da impostura quanto o reconhecimento de si mesmo no estranho ou estrangeiro.

O comportamento histérico e desesperado de adesão a coletivos pautados em uma socialização forçada e inteiramente atravessada pela síndrome in-group/outgroup, descrita por Freud como narcisismo das pequenas diferenças, configura-se como delírio continuamente reforçado por mecanismos de defesa que impedem o atingimento da autonomia emocional. E neste, "ao invés de elaborar intelectualmente o fracasso da pretensão absoluta e assim continuar a determinar seu juízo, o paranoico se aferra à pretensão que levou seu juízo ao fracasso" (ADORNO e HORKHEIMER, 1985, p. 181). A análise das necessidades emocionais que explicam o sucesso do fascismo, bem como a dialética envolvida nesse processo, que, conforme observou-se, consiste no reforço contínuo de um comportamento de adesão histérica, que não é imune a uma consciência latente acerca de sua própria impostura, é abordada analogamente por Adorno em texto escrito em parceria com o americano George Simpsom. Em Sobre música popular, Adorno aborda mais detalhadamente o pano de fundo emocional subjacente à adesão fascista, analisando o fenômeno dos autodenominados jitterbugs, os fãs de bandas de música comercial americana nos anos 1940.

Entre fãs de jazz e swing da época, Adorno constata a neutralização da possibilidade do indivíduo de efetivamente realizar escolhas autônomas no campo musical, em virtude do fato de que a relação de uma pessoa isolada com a indústria cultural é mediada pelo poder de monopólios econômicos que atuam na mercantilização da cultura. $\mathrm{O}$ que produz o efeito socialmente nefasto de interferir decisivamente na própria liberdade de escolha individual. Dessa forma, o comportamento social do fã da música de massa é fortemente influenciado pela "sapiência" das multidões que por meio de sua adesão entusiasmada corroboram o poder das agências de controle. Gostos e opiniões dissonantes são ameaçados pela não integração social, possibilidade aterrorizadora para um indivíduo solitário impotente, para o qual "a resistência é encarada como um sinal de má cidadania, como incapacidade de se divertir, como falta de sinceridade do pseudointelectual, pois qual é a pessoa normal que poderia se colocar contra essa música normal? " (ADORNO e SIMPSON, 1986, p. 142).

Diante de procedimentos sistemáticos de repetição do conteúdo musical e de simultâneo reforço da força dos monopólios culturais, desproporcionalmente poderosos perante um indivíduo singular, a capacidade de resistência individual é seriamente comprometida, embora não seja simplesmente eliminada. A energia que poderia ser concretizada como resistência ao estado social de heteronomia é investida sob a forma de comportamentos que reforçam a própria manipulação do gosto musical pelas agências da indústria cultural.

Segundo Adorno e Simpson, as preferências musicais são histericamente e ativamente defendidas contra possíveis críticas que possam apontar a manipulação subjacente ao processo como um todo. A servidão voluntária é hiper-reforçada, contra sentimentos de vergonha que seriam acarretados pela confissão de dependência, "por isso, eles voltam o seu ódio antes contra aqueles que apontam a sua dependência do 
que contra aqueles que apertam as suas algemas" (1986, p. 142).

De maneira análoga à análise da impostura realizada no texto sobre teoria freudiana e propaganda fascista, Adorno aponta o caráter ambíguo subjacente à adesão fanática à música de consumo massificado. Nos dois planos de desvendamento da adesão ao fascismo, os potenciais latentes de superação da impostura são neutralizados pela obstinação dedicada à manutenção de um equilíbrio psicologicamente precário entre as fortes pressões sociais exercidas em nome de uma integração totalitária e das demandas narcísicas que impedem uma compreensão crítica sobre a manipulação envolvida no processo de adesão.

$\mathrm{Na}$ análise dos jitterbugs, o pensador apresenta com notável precisão a configuração emocional de engano voluntário que caracteriza o fã de música popular, sob a forma de uma imagem que analogamente é relevante para dar conta da adesão ao fascismo em si mesmo, independentemente do contexto social específico ou da ideologia em nome da qual se dá a integração do indivíduo no coletivo. A imagem adorniana apresenta tanto o frenesi histérico, furioso e próprio desse tipo de integração como também sua recusa prévia e ressentida em relação a conteúdos que possam apontar para uma possível superação da alienação coletiva. Segundo Adorno,

o fã da música popular precisa ser imaginado como percorrendo o seu caminho com olhos firmemente fechados e dentes cerrados a fim de evitar que se desvie daquilo que decidiu aceitar. Uma visão clara e calma colocaria em perigo a atitude que lhe foi infligida e que, por sua vez, ele tenta infligir a si mesmo (1986, p. 145).

\section{IMPOSTURA E AUTOENGANO}

Os parágrafos finais desses dois textos em que Adorno analisa a adesão fascista apresentam como ponto comum a existência de uma dialética intrínseca ao fascismo, na qual os elementos latentes de superação da integração forçada ao coletivo tornam-se tanto mais manifestos e potencialmente realizáveis na mesma medida em que aumenta o esforço necessário do indivíduo para se convencer da impostura necessária para manter a integração. Esse aumento de energia psicologicamente mobilizada para preservar o estado coletivo de autoengano deve-se ao fato de que a prática política dos regimes autoritários, ao exigir submissão absoluta de seus integrantes, estabelece uma contradição flagrante em relação a indivíduos que não deixam de ser integrantes de uma sociedade liberal, tecnologicamente evoluída e potencialmente esclarecida.
A contradição entre as demandas fascistas de sujeição e os potenciais de esclarecimento da era moderna que não podem ser simplesmente eliminados converte a ideologia autoritária em "mentira manifesta", cuja manutenção exige um grande esforço psicológico para a preservação do autoengano. Sob esse aspecto, Adorno comenta a existência de um "fino véu", entre a impostura e sua consciência crítica cujo rompimento, paradoxalmente, "é quase insuperavelmente difícil" (1986, p.146). Entretanto, em nome da dificuldade extrema da tarefa de autoconsciência, não se pode negligenciar o quanto o esforço do indivíduo para absorver conteúdos ideológicos cada vez mais evidenciados como mentira manifesta, apesar de fortalecer a adesão ao fascismo, acaba por produzir também elementos potenciais para seu esclarecimento racional e consequente dissolução. É sob esse quadro que se pode compreender o estilo análogo com que Adorno conclui ambos os textos, expondo a dialética intrínseca ao fascismo:

\begin{abstract}
A hipnose socializada cria no interior de si mesma as forças que eliminarão o fantasma da regressão por controle remoto, e que, no fim, despertarão aqueles que mantêm seus olhos fechados apesar de não estarem mais dormindo (2015, p. 188).

Para ser transformado em um inseto, o homem precisa daquela energia que eventualmente poderia efetuar a sua transformação num homem (1986, p. 146).
\end{abstract}

A perspectiva dialética de reverter contra o fascismo a mesma energia investida em sua reprodução animou igualmente outros escritos de Adorno dedicados ao tema, dentre eles destacando-se Liderança democrática e manipulação de massas, escrito em 1951. Nesse texto, o teórico analisa a disseminação de tendências fascistas como consequência do desvanecimento da liderança democrática e igualmente da própria substância das instituições democráticas, solapadas pela hegemonia de uma política do ticket. Por meio destas, os eleitores são destituídos como sujeitos autodeterminados e reduzidos a meros objetos aptos a subscrever os interesses de grandes corporações burocráticas e econômicas. A liderança política assume um caráter rígido e autônomo, reduzindo a democracia a uma condição meramente formal e legitimadora de uma política totalitária, que, embora seja exercida por dentro do sistema democrático, culmina na fomentação de tendências antidemocráticas. Nesse texto, novamente relevando a necessidade de que o estado de autoengano voluntário possa ser revertido contra o fascismo, como um "efeito bumerangue", Adorno explicita seu propósito de derivar, do conhecimento dos expedientes mobilizados pelos líderes fascistas, conhecimentos que possam desempenhar o papel de "vacinas antifascistas". 
Ciente de que uma "imunização" contra o fascismo envolve necessariamente o enfrentamento das poderosas necessidades emocionais satisfeitas pelo envolvimento nos coletivos fascistas, o filósofo explicita o "ponto crítico" a ser atacado, que reside no ressentimento contra o esclarecimento racional: "É como se a energia da fúria cega fosse dirigida contra a idéia de verdade mesma, como se a mensagem saboreada pela audiência fosse inteiramente diferente de sua apresentação pseudamente factual" (2016, p. 4).

Para a realização desse objetivo, Adorno pondera que a mera reiteração da falsidade das mensagens preconceituosas e dos boatos divulgados pela liderança fascista não bastaria para demover a audiência, uma vez que a intensidade da gratificação emocional experimentada bloqueia justamente a capacidade racional de examinar a realidade de uma maneira minimamente isenta. Por esse motivo, juntamente com Horkheimer, ele trabalhou na elaboração de um manual capaz de desvendar os expedientes e mecanismos psicológicos mobilizados pelo líder para envolver a audiência. $\mathrm{O}$ pressuposto fundamental da estratégia dos filósofos para atacar a sedução fascista consistiu em mobilizar o preconceito com o objetivo de dissolver sua estereotipia rígida com base em uma motivação de caráter narcísico. A revelação da má-fé e da insinceridade da liderança fascista, juntamente com o menosprezo intrínseco desta em relação a seus seguidores, poderia inverter o sentido das catexias emocionais, fazendo-as voltarem-se contra o líder, uma vez que "ninguém, e menos ainda a personalidade potencialmente fascista, deseja ser tratado como trouxa" (ADORNO, 2016, p. 7).

No que se refere ao preconceito em si mesmo, apoiando-se nesse possível efeito bumerangue dirigido contra o líder, Adorno propõe a dissolução das tendências projetivas em relação ao unheimlich, mediante a demonstração do que antes denominou-se como caráter intercambiável das vítimas do fascismo; em outras palavras, pela explicitação da "causalidade, arbitrariedade e debilidade do objeto escolhido" (2016, p.7). A consciência sobre tal arbitrariedade poderia despertar a dúvida acerca da própria veracidade dos argumentos frágeis mobilizados para defender o preconceito. Sua dissolução dependeria, portanto, de uma inflexão subjetiva capaz de destruir a catexe negativa contra as vítimas, pois "quando eles aprenderem que quem eles odeiam é menos importante do que o fato de que eles odeiam alguma coisa, seus egos poderiam deixar de lado o ódio e, por aí, poderia ser que a intensidade de sua agressividade diminuísse" (ADORNO, 2016, p. 7).

As dificuldades inerentes a essa modalidade de esclarecimento não foram ignoradas por Adorno. $\mathrm{Na}$ Dialética do esclarecimento, juntamente com
Horkheimer, o teórico aponta os motivos que explicam a rigidez e muitas vezes a brutalidade que acompanham o delírio alucinatório que persiste na recusa intransigente de aceitar e reconhecer o unheimlich no interior de si próprio. O pensamento identitário e estereotipado, alérgico à autorreflexão e à consideração de mediações negativas por meio das quais as contradições reais podem ter acesso à consciência, foi um recurso primordial para a sobrevivência da espécie humana diante dos diversos desafios e contextos hostis enfrentados desde a préhistória.

Valendo-se de elementos da teoria evolucionista das espécies, Adorno ressalta a importância do estilo paranoico de representar a realidade, por meio da transferência para o objeto de suas próprias tendências hostis e agressivas, considerando que, para a sobrevivência da espécie humana, foi essencial "a força dos mecanismos de projeção" (1985, p. 182). Sob esse aspecto, o automatismo e a rigidez da projeção tornam-se um problema quando desacompanhados de processos reflexivos que sejam capazes de explicitar seu caráter obsoleto no contexto de uma sociedade burguesa dotada de elevados potenciais de esclarecimento racional. $\mathrm{O}$ diagnóstico aqui apresentado sobre as tendências regressivas e destrutivas do fascismo, bem como acerca de um possível antídoto que possa imunizar os espíritos diante da atração exercida pelas coletividades fascistas, é o mesmo posteriormente anunciado para uma educação contra a barbárie: "O único poder efetivo contra o princípio de Auschwitz seria autonomia, para usar a expressão kantiana; o poder para a reflexão, a autodeterminação, a não-participação" (ADORNO, 1995, p. 125).

\section{ANTÍdoto CONTRA o FASCISMO: A AUTORREFLEXÃO SOBRE A SUBJETIVIDADE}

A relevância do esclarecimento racional para uma educação contra o fascismo, quando pensada dialeticamente, revela ao educador obstáculos nada simples de serem removidos. Isso porque a mais simples consideração das dificuldades socialmente postas a essa tarefa expõe um problema nada fácil de ser enfrentado: como é possível educar contra o fascismo, mediante o fortalecimento das instâncias racionais de resistência à barbárie sob contextos culturais nos quais é hegemônica a semiformação e o ressentimento cultural que necessariamente a acompanha?

Em outras palavras, todos são necessariamente conduzidos a se interrogar acerca da própria possibilidade de uma educação emancipadora sob contextos nos quais a educação não se constitui como processo dialético de apropriação da cultura, mas sim em veículo de adaptação unidimensional. Além disso, é preciso considerar que a 
consciência semiformada não se caracteriza somente pela inaptidão a processos de esclarecimento racional, mas, adicionalmente, constitui-se em instância ressentida, e, portanto, previamente hostil aos potenciais de autonomia presentes na cultura. Em debate de 1968, intitulado $A$ educação contra a barbárie, Adorno apontou com precisão a hostilidade prévia de uma consciência semiformada a impulsos formadores e autorreflexivos capazes de dissipar o véu encobridor que a separa de sua verdade interna. Sob esse aspecto, vale lembrar que a consciência semiformada é atravessada por uma hostilidade furiosa análoga àquela peculiar aos jitterbugs, em sua histérica e fanática adesão à indústria cultural:

penso que, além desses fatores subjetivos, existe uma razão objetiva da barbárie, que designarei bem simplesmente como a da falência da cultura. A cultura, que conforme sua própria natureza promete tantas coisas, não cumpriu a sua promessa. Ela dividiu os homens. A divisão mais importante é aquela entre trabalho físico e intelectual. Deste modo ela subtraiu aos homens a confiança em si e na própria cultura. E como costuma acontecer nas coisas humanas, a consequência disto foi que a raiva dos homens não se dirigiu contra o nãocumprimento da situação pacífica que se encontra propriamente no conceito de cultura. Em vez disto, a raiva se voltou contra a própria promessa ela mesma, expressando-se na forma fatal de que essa promessa não deveria existir (ADORNO, 1995, p. 164).

O paradoxo da existência de consciências altamente vulneráveis ao fascismo, que são ao mesmo tempo previamente imunizadas contra potenciais formativos que poderiam permitir a elaboração autor reflexiva da síndrome autoritária, remete à própria dialética do esclarecimento, na medida em que se está diante de uma racionalidade anulada como veículo emancipador e afirmada como órgão posto a serviço da dominação patriarcal da natureza e dos próprios homens. A resposta adorniana a esse dilema, que havia sido inicialmente exposto na escrita da obra Dialética do esclarecimento, na década de 1940, encontrou sua exposição mais acabada duas décadas à frente, por meio de sua Dialética negativa.

A contradição estrutural de uma razão cujos potenciais formadores são anulados mediante um estado geral de semiformação, que é resultado histórico do próprio progresso técnico e racional, não pode ser simplesmente resolvida pelo apelo a soluções escapistas que denunciem o projeto moderno e iluminista como mera expansão desenfreada do poder. Isso implicaria negligenciar a estrutura dialética da razão. Nesse sentido, a filosofia de Adorno aponta para a priorização do momento negativo da dialética, de modo que, pela suspensão da síntese, a não identidade entre as coisas e seus conceitos possa preservar as ideias como signos negativos existentes entre a configuração imediata e empírica dos objetos e seus conceitos. A má consciência da razão em relação ao fracasso histórico de sua promessa de ampliação dos horizontes da liberdade e da autonomia deve conduzir a uma insistência sistemática no princípio de que, embora a identidade conceitual seja mecanismo de sujeição, é somente mediante a identidade que se volta contra sua falsa identidade que será possível a libertação da sujeição. Esse movimento dialético de tensionamento entre a força da consciência e as ilusões por ela mesma produzidas justifica a construção emblemática com que Adorno iniciou sua Dialética negativa: "A filosofia, que um dia pareceu ultrapassada, mantém-se viva porque se perdeu o instante de sua realização" (2009, p. 11).

Transferida para o campo da educação, a dialética negativa exige que a semiformação e o ressentimento voltados contra a cultura sejam elaborados mediante processos autor reflexivos que se voltem contra a transformação dos educandos em meros objetos de administração técnica. À reflexão filosófica no campo educativo está endereçado o papel de expor, refletir e visualizar a superação das contradições intrínsecas ao estado hegemônico de heteronomia, claramente diagnosticado por Adorno quando definiu o imperativo relacionado a uma educação após Auschwitz: "Desbarbarizar tornou-se a questão mais urgente da educação hoje em dia" (1995, p.155). O tema da desbarbarização remete necessariamente a uma educação dedicada à dissolução da estereotipia e dos diversos tipos de preconceito que favorecem a incapacidade de elaboração dos sentimentos de estranheza e de hostilidade em relação ao unheimlich. Implica igualmente a geração e o fortalecimento de elementos formativos que favoreçam o rompimento do fino véu que separa a impostura de sua conscientização crítica e negativa, para que uma personalidade autônoma possa emergir em movimento contrário às tendências hegemônicas de perpetuação do autoengano.

Nesse sentido, uma educação contra o fascismo, nos moldes filosoficamente propostos por Adorno, sugere o fortalecimento da cultura, entendida como apropriação viva do espírito, em um movimento negativo capaz de atuar na direção contrária às tendências hegemônicas perpetuadoras das gratificações emocionais que retroalimentam o estado geral de frieza e regressão.

Considerando que o fascismo não é, de nenhuma maneira, um desvio acidental da rota triunfal e linear do progresso, mas, pelo contrário, o resultado necessário da expansão patriarcal do poder dos homens sobre a natureza, sua superação exige a mobilização dos potenciais 
emancipadores do esclarecimento que permanecem vivos e atuais mesmo diante do fracasso da sua promessa de liberdade e de felicidade.

Se o fascismo é histórico, ele é necessariamente passível de superação.

\section{REFERÊNCIAS}

ADORNO, T. W. Sobre música popular. In: COHN, G. (Org.). Theodor W. Adorno. São Paulo: Ática. 1986.

ADORNO, T. W. Educação e emancipação. Trad. de Wolfgang Leo Maar. Rio de Janeiro: Paz e Terra, 1995.

ADORNO, T. W. Minima moralia. Trad. de Gabriel Cohn. Rio de Janeiro: Beco do Azougue, 2008.
ADORNO, T. W. Dialética negativa. Trad. de Marco Antonio Casanova. Rio de Janeiro: Zahar, 2009.

ADORNO, T. W. Ensaios sobre psicologia social e psicanálise. Trad. de Verlaine Freitas. São Paulo: Editora da Unesp, 2015.

ADORNO, T. W. Liderança democrática e manipulação de massas. Disponível em: <http://adorno.planetaclix.pt/>. Acesso em: jul. 2016.

ADORNO, T. W.; HORKHEIMER, M. Dialética do esclarecimento. Trad. de Guido Antonio de Almeida. Rio de Janeiro: Zahar, 1985.

FREUD, S. Mal-estar na civilização. Trad. de José Octavio de Abreu. Rio de Janeiro: Imago, 1974.

Recebido em 08-12-2016.

Aprovado em 30-07-2017. 